\title{
Antiretroviral Therapy for Mitochondrial Toxicity in HIV-Infected Pregnant Women
}

\section{Tamuzi $\mathrm{JL}^{1 *}$ and Tshimwanga $\mathrm{JL}^{2}$}

${ }^{1}$ Faculty of Medicine and Health Sciences, Division of Community Health, Stellenbosch University, Matieland, South Africa ${ }^{2}$ Faculty of Medicine and Health Sciences, Division of Family Medicine, Stellenbosch University, Matieland, South Africa

\begin{abstract}
Background: The use of antiretroviral therapy (ART) in HIV-infected women is crucial to restore and maintain the immune system and prevent HIV transmission during pregnancy, labor, delivery and breastfeeding. Furthermore, ART reduce the risk of Mother-to-child transmission (MTCT). Therefore, ART has been associated with mitochondrial defections that could induce preeclampsia, preterm birth, low birthweight, intrauterine growth restriction (IUGR), stillbirth and sudden infant death.
\end{abstract}

Objective: To evaluate the effect of antiretroviral therapy on mitochondrial defections in HIV-infected pregnant women.

Methods: We searched eligible studies in MEDLINE, Scorpus and WHO Global Index Medicus. Included studies were assessing the effects of antiretroviral therapy on genetic mitochondrial diseases in HIV infected pregnant women and HIV exposed infants. JTL searched eligible studies in different databases and both JLT and JLT critically appraised included studies.

Results: We found five observational studies with low risk of bias. All studies illustrated that ART increased the mean of mitochondrial defections. The results were statistically significant in all studies with $\mathrm{P}<0.05$.

Conclusion: Mitochondrial lesions were very common in HIV infected pregnant women and HIV exposed infants. However, further investigations are needful to strengthen this evidence.

Keywords: Antiretroviral treatment; HIV; Infants; Pregnancy; Mitochondrial defections

\section{Introduction}

HIV prevalence in Sub-Saharan Africa is the highest worldwide, with 25.6 million people living with HIV in 2015 [1]; among them, $58 \%$ women are HIV infected [2]. MTCT is the highest in the world in Sub-Saharan Africa. The use of antiretroviral therapy (ART) in ante and postpartum period is crucial both for preserving maternal health and for PMTCT of HIV [3]. The effectiveness of ART regimens in reducing MTCT of HIV-infection and delaying disease progression has been demonstrated. Then, ART should be offered to all pregnancies as stipulated by the World Health Organization (WHO) [4]. However, systematic reviews have shown that ART in HIV-infected women has been associated with preeclampsia, preterm birth, low birthweight, intrauterine growth restriction (IUGR), stillbirth and sudden infant death, particularly in sub-Saharan Africa. Molecular medicine has illustrated that ART may cause severe mitochondrial dysfunction. A recent study ranks ART mitochondrial toxicities as follows (from the most to the less harmful): (ddC). didanosine (ddI) $>$ stavudine $(\mathrm{d} 4 \mathrm{~T})>$ Zidovudine $(\mathrm{AZT})>$ lamivudine $(3 \mathrm{TC})>$ abacavir $=$ tenofovir (TDF) [5]. In Sub-Saharan Africa, TDF/3TC based regimens are widely prescribed in HIV-infected pregnant women. This regimen could lead to additive effects and cause more mitochondrial dysfunctions. The prevalence of ART associated to toxicities is reported to be more than $47 \%$ and $27 \%$ for clinical and laboratory manifestations, respectively [6]. The commonest mitochondrial DNA deletion is the most common mtDNA deletion in mitochondrial dysfunction [6]. These negative effects depend on the capacity of the NRTI to inhibit DNA g-polymerase, the only enzyme devoted to the replication mtDNA genome, inducing then a decrease in mtDNA copy number and quality, which, in turn, may finally cause mitochondrial defections [7]. As mtDNA encodes for respiratory chain enzyme subunits, a defect in oxidative phosphorylation (OXPHOS) may result because mitochondrial proteins (mtprotein) could be defected [5]
In fact, mitochondrial defections have been associated with increased rates of preterm delivery, stillbirth, IUGR, and sudden infant death [5-8]. Reviewing the literature, ART can induce subclinical transplacental mitochondrial lesions. Therefore, it is unknown whether HIV in pregnancy could injure mitochondria. Mitochondrial defections in a given organism could lead to the development of mitochondriopathies [9].

Mitochondriopathies are classified as inherited or acquired (derived from toxic substances), with both sharing similar clinical consequences [10]. This scientific paper is focused on acquired mitochondriopathies due to ART affecting both mitochondrial DNA and proteins. The mutations responsible for genetic mitochondrial diseases can be present in both the nuclear or mitochondrial genome [10]. Genetic mitochondrial diseases are already present in 1 in 5000 newborns and 1 in 200 women may carry one of these deleterious mutations [11]. Studies have shown that ART highly increase mitochondrial mutations.

\section{Objectives}

To evaluate the effects of antiretroviral therapy on mitochondrial defections in HIV-infected pregnant women and HIV exposed infants.

${ }^{*}$ Corresponding author: Dr. Jacques Lukenze Tamuzi, Faculty of Medicine and Health Sciences, Division of Community Health, Stellenbosch University, Matieland, South Africa, Tel: +27218089111; E-mail: drjacques.tamuzi@gmail.com

Received December 19, 2017; Accepted December 28, 2017; Published December 29, 2017

Citation: Tamuzi JL, Tshimwanga JL (2017) Antiretroviral Therapy for Mitochondrial Toxicity in HIV-Infected Pregnant Women. J Mol Genet Med 11: 315 doi:10.4172/1747-0862.1000315

Copyright: ( 2017 Tamuzi JL, et al. This is an open-access article distributed under the terms of the Creative Commons Attribution License, which permits unrestricted use, distribution, and reproduction in any medium, provided the original author and source are credited 
Citation: Tamuzi JL, Tshimwanga JL (2017) Antiretroviral Therapy for Mitochondrial Toxicity in HIV-Infected Pregnant Women. J Mol Genet Med 11: 315 doi:10.4172/1747-0862.1000315

\section{Methods}

We systematically searched in MEDLINE, Scorpus and WHO Global Index Medicus. We included observational studies assessing the effects of antiretroviral therapy on genetic mitochondrial diseases in HIV infected pregnant women and HIV exposed infants.

The criteria for considering included studies for this mini review were HIV pregnant women on ART and HIV exposed newborn. We assessed maternal mtDNA depletion and newborn mtprotein. We included observational studies comparing cases and controls. We considered all types of ART regimens in HIV pregnant women. No other restriction criteria were imposed in terms of inclusion or exclusion studies.

JTL searched eligible studies in different databases. JLT and JLT worked independently to review full-text versions articles. The reviewers independently extracted data for study characteristics, patient characteristics, and outcomes (unadjusted and adjusted associations). Observational studies were assessed with Newcastle-Ottawa Scale. The following domains were used for bias assessment:

1. Is the case definition adequate?

2. Representativeness of the cases

3. Selection of controls

4. Definition of controls

5. Comparability of cases and controls on the basis of the design or analysis

\section{Ascertainment of exposure}

7. Same method of ascertainment for cases and controls

\section{Results and Discussion}

We screened a total number of 217 studies, and included 5 studies; four studies have been conducted in Spain and one in Canada. All the included studies were observational studies among which four crosssectional and one prospective cohort study. All of studies analyzed the occurrence of maternal mtDNA and mtprotein in infants.
We included 5 observational studies among which four cross sectional studies and one prospective cohort study $[5,7,8,12,13]$ (Table 1). The results were reported narratively. All mitochondrial studies conducting in HIV-pregnancies have described an increased frequency of mtDNA depletions.

The first study [8] reported the mean (SE) depletion of $44.45 \pm$ $3.77 \%$ with $\mathrm{P}=0.001$ in HIV-pregnant women and the mean (SE) $\mathrm{mt}$ proteins were reduced in HIV exposed infants compared to the control group $48.79 \pm 3.41 \%$ with $\mathrm{P}<0.001$. The second study [9] found $\mathrm{mt}$ proteins were reduced in HIV-infected pregnant women, infants and foetus with respectively: $25.8 \%, 38.6 \%$ and $13.6 \%(\mathrm{P}<0.05)$. The third study [10] reported the mean (SE) maternal mtDNA of $42.66 \pm 5.94 \%$ and $\mathrm{mt}$ proteins of $12.82 \pm 5.73 \%$. The mtDNA mean (SD) in the fourth study [11] was reduced by $39.20 \% \pm 2.78 \%$. The last study [12] revealed that the mean (SE) $\mathrm{mtDNA} / \mathrm{nDNA}$ ratio was reduced by $-18.0 \pm 6.1$. All the results were statistically significant $(P<0.05)$. All included studies were low risk of bias from 6 to 7 on Newcastle-Ottawa Scale [13].

\section{Conclusion}

Summary considerations on study quality in general, the studies did not show major problems of selection bias, the majority use the same population (HIV pregnant women and HIV exposed infants) compared to pregnant women HIV negative and HIV non-exposed infants respectively, limiting then problems of comparability. Multiple linear regressions were used in all included studies, and then adjustment for confounding factors was adequate. Ascertainment of outcome has not major biases in relation to the assessment of mtDNA and mtprotein because those outcomes are ascertained through laboratory record. Losses to follow-up would not possibly represent a problem. In most studies, losses to follow-up were not reported and the possible risk of bias is not predictable. All included studies included double-NRTI based regimens. Among them, three studies included AZT contained regimens $[5,7,8]$. As explained above, AZT based regimens may cause severe mitochondrial deflections implying highly statistically significant results in AZT based regimens studies.

A potential limitation of our search strategy is that only few databases were considered. It is likely to associated publication bias. However, this is a brief research has confirmed the results of previous

\begin{tabular}{|c|c|c|c|c|c|c|}
\hline Study ID & Study design & Settings & Participants & Interventions & Outcomes & $P$-value \\
\hline Moren et al. [10] & $\begin{array}{l}\text { Cross-sectional, } \\
\text { prospective, } \\
\text { observational, } \\
\text { exploratory and } \\
\text { controlled study. }\end{array}$ & $\begin{array}{l}\text { Hospital St Joan de } \\
\text { De'u of Barcelona } \\
\text { (Barcelona, Spain) }\end{array}$ & $\begin{array}{l}35 \text { HIV-infected pregnant } \\
\text { women and } 17 \text { controls }\end{array}$ & $\begin{array}{l}\text { AZT based regimens } \\
\text { and other NRTI } \\
\text { regimens }\end{array}$ & $\begin{array}{c}\text { (mtDNA) depletion } \\
\text { Mothers }(44.45 \pm 3.77 \%) \\
\text { Infants }(48.79 \pm 3.41 \%)\end{array}$ & $\begin{array}{l}P=0.001 \\
P<0.001\end{array}$ \\
\hline $\begin{array}{l}\text { Herna`ndez et } \\
\quad \text { al. [7] }\end{array}$ & $\begin{array}{l}\text { Single-site, cross- } \\
\text { sectional, controlled } \\
\text { observational study } \\
\text { without intervention. }\end{array}$ & $\begin{array}{l}\text { Hospital Clinic } \\
\text { of Barcelona } \\
\text { (Barcelona, Spain). }\end{array}$ & $\begin{array}{l}27 \text { HIV-infected and treated } \\
\text { pregnant women, and } 35 \\
\text { uninfected controls }\end{array}$ & $\begin{array}{l}\text { NRTI contained } \\
\text { regimens }\end{array}$ & $\begin{array}{c}\text { Newborn mtprotein reduced: } \\
38.6 \% \\
\text { maternal mtprotein: } 25.8 \% \\
\text { Fetal mt protein: } 13.6 \%\end{array}$ & $P<0.05$ \\
\hline Hernandez et al. [5] & $\begin{array}{l}\text { Single-site, controlled } \\
\text { observational study }\end{array}$ & $\begin{array}{l}\text { Hospital Clinic } \\
\text { of Barcelona } \\
\text { (Barcelona, Spain) }\end{array}$ & $\begin{array}{l}\text { Pregnancy and delivery in } \\
27 \text { HIV-infected and treated } \\
\text { pregnant women versus } 24 \\
\text { uninfected pregnant controls. }\end{array}$ & $\begin{array}{c}\text { NRTI based regimens + } \\
\text { protease }\end{array}$ & $\begin{array}{c}\text { mtDNA reduced } \\
\text { Maternal: } 42.66 \pm 5.94 \% \\
\text { Mtprotein reduced: } 12.82 \pm \\
5.73 \%\end{array}$ & $\begin{array}{l}P<0.01 \\
P<0.01\end{array}$ \\
\hline Hernandez et al. [7] & $\begin{array}{l}\text { Single-site, cross- } \\
\text { sectional, controlled, } \\
\text { and observational } \\
\text { study }\end{array}$ & $\begin{array}{l}\text { Hospital Clinic of } \\
\text { Barcelona }\end{array}$ & $\begin{array}{c}24 \text { asymptomatic HIV-1- } \\
\text { infected pregnant women } \\
\text { and } 32 \text { uninfected pregnant } \\
\text { controls. }\end{array}$ & AZT based regimens & $\begin{array}{c}\text { mtDNA reduced } \\
\text { Maternal: } 39.20 \% \pm 2.78 \%\end{array}$ & $P<0.001$ \\
\hline Money et al. [13] & $\begin{array}{c}\text { Prospective } \\
\text { longitudinal } \\
\text { observational cohort } \\
\text { study }\end{array}$ & $\begin{array}{l}\text { Oak Tree Clinic, a } \\
\text { provincial referral } \\
\text { centre in Vancouver, } \\
\text { British Columbia } \\
\text { (BC), Canada }\end{array}$ & $\begin{array}{c}\text { (i)HIV+ women }(\mathrm{N}= \\
65) \text { using cART during } \\
\text { pregnancy (cART started } \\
\text { pre-conception or during } \\
\text { Pregnancy); (ii) HIV- women } \\
(\mathrm{N}=45) \text {. }\end{array}$ & $\begin{array}{l}\text { AZT contained } \\
\text { regimens and other } \\
\text { NRTI based regimens }\end{array}$ & $\begin{array}{c}\text { mtDNA/nDNA ratio } \\
-18.0 \pm 6.1\end{array}$ & $P=0.003$ \\
\hline
\end{tabular}

Table 1: Included studies. 
Citation: Tamuzi JL, Tshimwanga JL (2017) Antiretroviral Therapy for Mitochondrial Toxicity in HIV-Infected Pregnant Women. J Mol Genet Med 11: 315 doi:10.4172/1747-0862.1000315

Page 3 of 3

studies conducted on the effects of ART on mitochondrial diseases. Besides, we did not find any study conducted in Sub-Saharan Africa where HIV prevalence is the highest in the world.

In fact, ARTs are indispensable in the treatment and prevention of HIV infection. Until now, the use of ART during pregnancy is considered safe; therefore, there are still many concerns about maternal and foetal outcomes that are not clearly highlighted in clinical practice. Besides, certain ART regimens have more mitochondrial toxicities than others. By the way, specific ART regimens should be used in pregnancy. In addition, the timing of prescribing ART in pregnancy could lower mitochondrial toxicity. Then, mitochondrial toxicity associated to ART inducing newborn and maternal morbidity need further studies, particularly in Sub-Saharan Africa. This could establish whether HIVpregnancy may be an additional risk for the onset of mitochondrial toxicity, because it is currently unknown.

\section{Acknowledgments}

We sincerely thank the Journal of Molecular and Genetic Medicine for publishing this brief research communication.

\section{References}

1. WHO (2016) HIVIAIDS. In: Media center.

2. www.unaids.org/UNAIDS_FactSheet-en.pdf 2016

3. Nachega JB, Uthman OA, Anderson J, Peltzer K, Wampold S, et al. (2012) Adherence to antiretroviral therapy during and after pregnancy in low-income, middle-income, and high-income countries: A systematic review and metaanalysis. AIDS 26: 2039-2052.
4. Dieffenbach CW, Fauci AS (2011) Thirty years of HIV and AIDS: Future challenges and opportunities. Ann Intern Med 154: 766-771.

5. Hernandez S, Moren C, Catalan-Garcia M, Lopez M, Guitart-Mampel M, et al. (2017) Mitochondrial toxicity and caspase activation in HIV pregnant women. J Cell Mol Med 21: 26-34.

6. Li M, Foli Y, Liu Z, Wang G, Hu Y, et al. (2017) High frequency of mitochondrial DNA mutations in HIV-infected treatment-experienced individuals. HIV Med 18 $45-55$

7. Hernandez S, Moren C, Lopez M, Coll O, Cardellach F, et al. (2012) Perinatal outcomes, mitochondrial toxicity and apoptosis in HIV-treated pregnant women and in-utero-exposed newborn. AIDS 26: 419-428.

8. Moren C, Hernandez S, Guitart-Mampel M, Garrabou G (2014) Mitochondrial toxicity in human pregnancy: An update on clinical and experimental approaches in the last 10 years. Int J Environ Res Pub Health 11: 9897-9918.

9. Hernandez S, Catalan-Garcia M, Moren C, Garcia-Otero L, Lopez M, et al (1999) Placental mitochondrial toxicity, oxidative stress, apoptosis, and adverse perinatal outcomes in HIV pregnancies under antiretroviral treatment containing zidovudine. J Acq Imm Def Synd 75: e113-119.

10. Moren C, Noguera-Julian A, Garrabou G, Rovira N, Catalan M, et al. (2015) Mitochondrial disturbances in HIV pregnancies. AIDS 29: 5-12.

11. Mando C, De Palma C, Stampalija T, Anelli GM, Figus MN, et al. (2014 Placental mitochondrial content and function in intrauterine growth restriction and preeclampsia. Am J Physiol Endocrinol Metab 306: E404-E413.

12. Robert TW, Doug TM (2005) Mitochondrial DNA mutations in human disease Nat Rev Genet 6: 389-391.

13. Money DM, Wagner EC, Maan EJ, Chaworth-Musters T, Gadawski I, et al. (2015) Evidence of subclinical mtDNA alterations in HIV-infected pregnant women receiving combination anti-retroviral therapy compared to HIV-negative pregnant women. PLoS One 10: e0135041. 